\title{
ORGANISATIONAL SEMIOSIS: INTEGRATION AND SEPARATION BETWEEN SYSTEM FEATURES AND WORKPRACTICES
}

\author{
Rodney J Clarke \\ Department of Business Systems, University of Wollongong \\ Northfields Avenue, North Wollongong, NSW Australia, 2500 \\ Phone: +61024221 3752 Fax: +610242214474 \\ E-mail: rodney_clarke@uow.edu.au \\ WWW: http://www.uow.edu.au/commerce/buss/sysco.htm
}

\begin{abstract}
Traditional information systems theory and practice assumes a tight coupling or integration between workpractices in organisations and the information systems which are notionally built to support them. The relationship between the integration and the separation of workpractices and system features has been theorised as dialectical. It has also been argued that the goal of system design would be to achieve a dynamic equilibrium within this dialectic.

However, this paper argues that the above mentioned dialectic forged between integrationist and separationist views can be usefully critiqued by applying systemic semiotics. Systemic semiotics refers to a combination of systemic functional linguistics (a semiotic model of language) and its extensions into a general semiotic framework called social semiotics. The latter draws heavily on the notion of dialogism which this paper proposes is useful in rethinking the relationship between workpractices and information systems. In addition, concepts of text and context are drawn from systemic functional linguistics in analysing the workpractices associated with the use of actual information systems features. Two examples are used to explicate this dialogic relationship, including: (i) the dynamic renegotiation of a workpractice which is assumed to be closely integrated to a system feature (negotiated separation), and (ii) the extension of the system into other locations by means of communicatively organising materials and users in the workplace (indirect integration).
\end{abstract}

\section{INTRODUCTION}

Goldkuhl (1993) questions a prevailing assumption within the Information Systems discipline that designers should work to create a tight integration between workpractices or activities in organisations, and the information system features designed to support them. While current design practices assume Integration, he notes that there have been periods throughout the history of IS design when a Separation between workpractices and systems features has been assumed- a conclusion easily substantiated in the literature. Goldkuhl proposes that IS designers should consider system features simultaneously from a basis of Integration- assuming system features are tightly coupled to a workpractice, and Separation- assuming system features are loosely coupled to a workpractice. In order for system designs to be evaluated simultaneously from these two standpoints, either distinct integration-oriented and separation-oriented design practices must be used, or alternative practices must be applied or developed which can facilitate this kind of design evaluation (see Figure 1a). Modelling the design of any given system feature twice using integration-oriented and separation-oriented design practices is generally impractical in terms of time and effort. However, Goldkuhl (1993) employs methods, originally developed in the ISAC systems development methodology, to demonstrate how several system features may be considered from both integrationist and separationist standpoints.

Goldkuhl's (1993) work has important implications for the development of organisational semiotics ${ }^{1}$, since the use of an information system could also be considered from integrationist and separationist standpoints. A movement from the domain of system design to that of systems use requires:

- substituting the planned functionality afforded by systems design with the actual functionality afforded by systems implementation of specific information systems features, while also

- substituting the proposed organisational activity to be supported or created using the information system, with enacted workpractices in organisational contexts

The only exception to a general agreement with Goldkuhl's (1993) thesis, is that there is, or should be, a dialectical relationship between Integration and Separation in design and, by extension, systems use. Williams (1988, 106-108) defines 'dialectic' in terms of the "continual unification of opposites, in the complex relation of parts to wholes [emphasis own]". As there appears to be no complex relation evident between Integration and Separation, there is cause to question the existence of a dialectical relationship between these concepts in systems design and by extension in system use. In the following section, integration and separation will be reconsidered as a dichotomy to be deconstructed using Derrida's reading tactics (Norris 1982).

Figure 1: (a) shows the Dialectical Relationship between Integration and Separation in Systems Design (after Goldkuhl 1993), while (b) shows a Dialogical Relationship between Integration and Separation in Systems Use. 
(a)

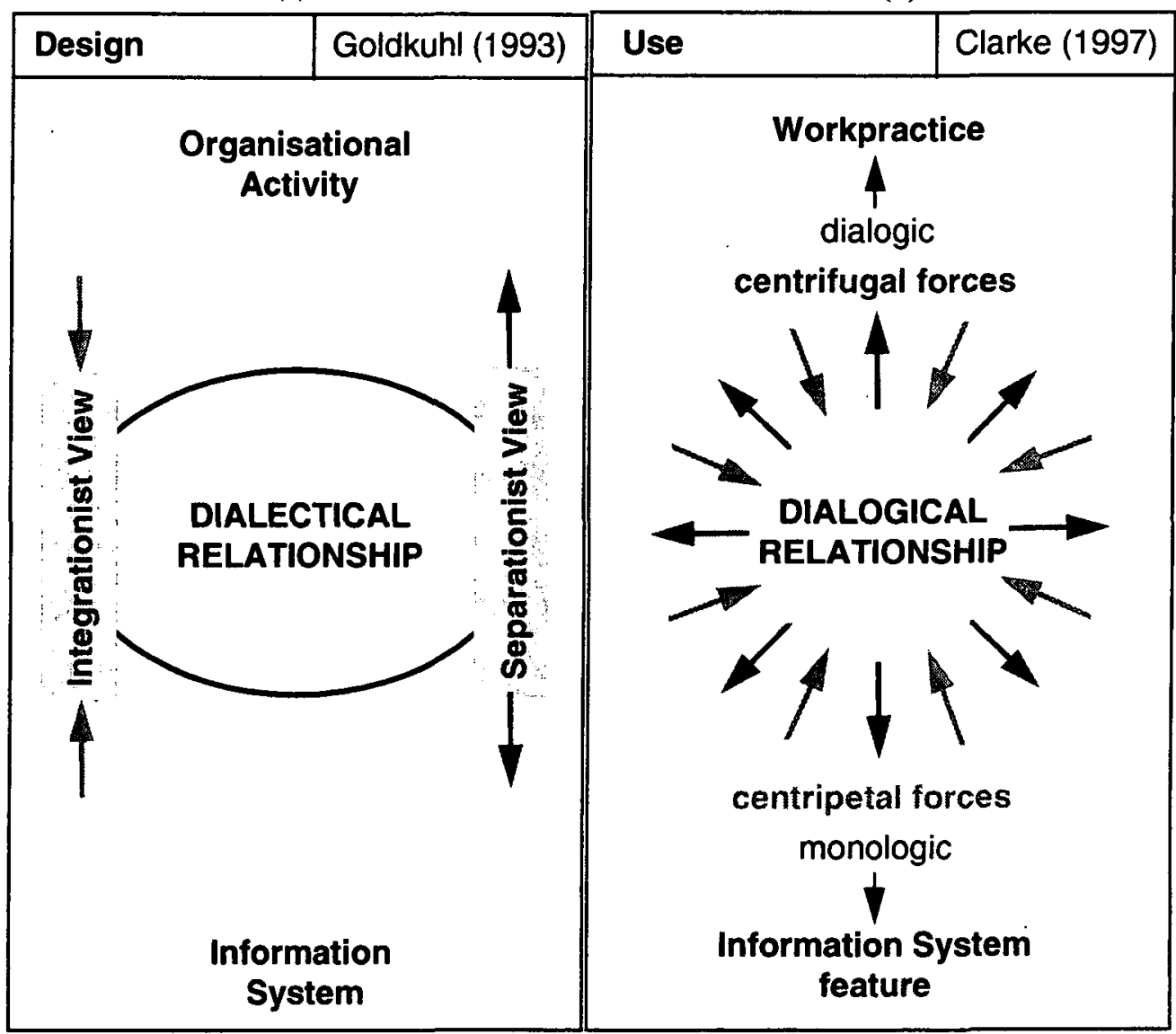

\section{INTEGRATION AND SEPARATION AS A DICHOTOMY}

Integration and Separation appear to be end points or extrema along a simple cline or grade- the degree of binding between a workpractice and a system feature. Consequently, in systems design and use, a 'large' degree of Integration presupposes a 'small' degree of Separation, and visa versa. Demonstrating that Integration and Separation are in a kind of proportional rather than a dialectical relationship shows that the relationship between these entities is actually a dichotomy, see Figure 2a. Dichotomies in social theory often function to suppress one of their terms, that is, dichotomies are not equally balanced. Derrida's deconstruction provides a set of reading tactics for interrogating dichotomies (Norris 1982).

The first deconstructive tactic used to interrogate the Integration/Separation dichotomy, is reversal, that is we reverse the relative positions of the two terms in privileging Separation, refer to Figure $2 b$. Reversal enables us to demonstrate that Integration and Separation are not logically necessary or unalterable in their relationship to each other. 
Figure 2: In (a), the terms Integration and Separation are shown as a dichotomy, see the upper panel, with the dominant term highlighted, in the lower panel. In (b), the dichotomy is interrogated using Derrida's reading tactics (see text).

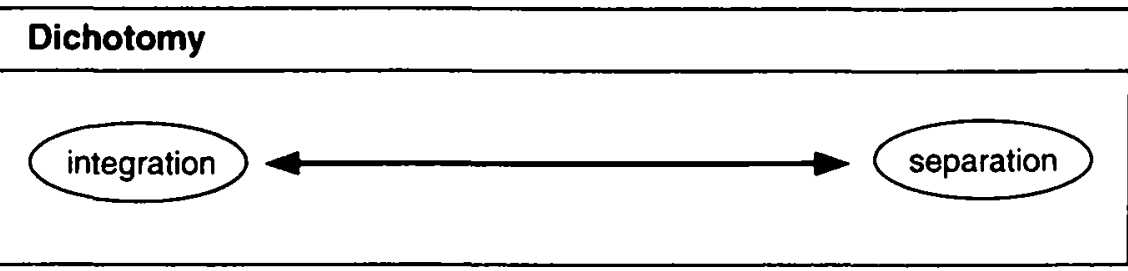

(a)

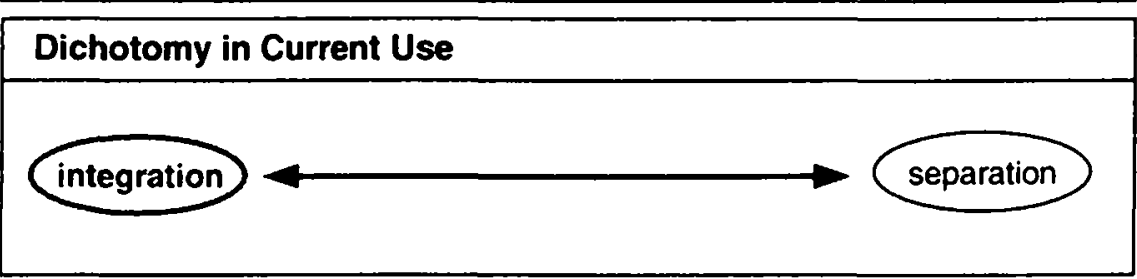

\section{Reading Tactics (Derrida 1988)}

\section{1: Reversal}

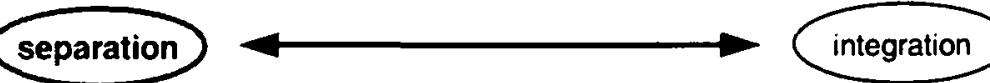

(b)

\section{2: Displacement}

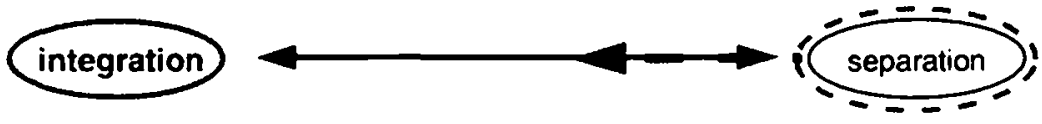

3: Hinge

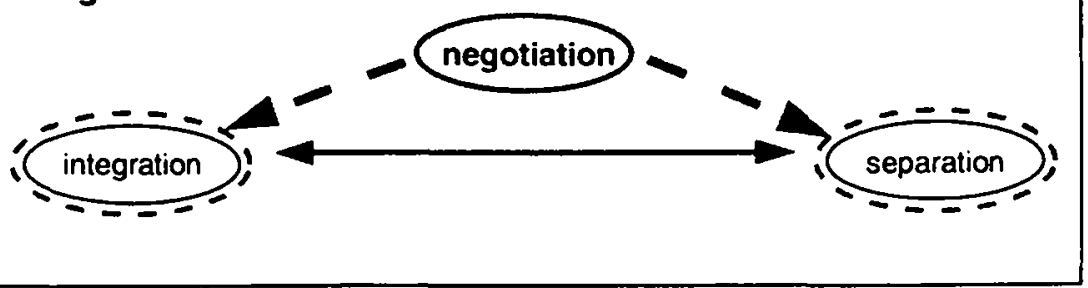

As noted earlier, Goldkuhl (1993) uses the literature to disrupt the dominance of Integration, while at the same time valuing the repressed term Separation. However, such an operation still preserves the dichotomous relationship between the two terms. Derrida's second deconstructive tactic is referred to as displacement. The repressed term Separation must be displaced, not out of the dichotomy altogether but by positioning it within the core of the dominant term as its logical condition. This makes explicit the unacknowledged debt that the dominant term of Integration owes to the secondary term of Separation. By demonstrating that the Integration/Separation dichotomy may not be logically necessary, the tactic of displacement foregrounds the fact that the dichotomy could be replaced by entirely different concepts.

The third reading tactic for interrogating dichotomies is the creation of a relevant hinge term which is 'outside' the binary opposition between integration and separation but which participates in both terms. A hinge term may be derived from texts being examined or it might be a neologism devised to interrogate a specific dichotomy. The function of the hinge term is to provide a logical precondition from which the dichotomy is constructed. The 
hinge term is in effect that which is leftover, unrepresented and uncontained by the dichotomy. Parenthetically, we have used the term 'reading tactics' as a way of avoiding using the term method since Derrida's 'reading tactics' do not suggest, for example, any candidates for the hinge term. The hinge term employed here to interrogate the dichotomy is negotiation. Negotiation is the logical precondition from which the Integration/Separation dichotomy is constructed in information systems theory. In using this term we foreground the fact that Integration or Separation between workpractices and information systems features is never historically fixed, but rather is always at risk. As a hinge term, negotiation is compatible with Goldkuhl's (1993) aim of describing a 'dynamic view' of the relationship between information system features and organisational activities. The choice of the term negotiation is strategic because it enables the relationship between workpractices and information systems to be theorised as dialogic according to Mikhail Bakhtin's sense of the term (Todorov 1992), and as applied in Clarke (1992).

\section{INTEGRATION AND SEPARATION AS DIALOGIC}

Bakhtin's research involved the development of translinguistics and was applied to the study of the novel, which at the time was a relatively recent literary genre. He focused on developing a dynamic theory of language and meaning emphasising the interrelationship between three categories: (i) the active and productive capacity of language; (ii) the evaluative nature of meaning; and (iii) social subjectivity. According to Todorov's (1984) reading of Bakhtin's work, the first category involves discourse which is theorised in terms of the production of actualised meaning in a communicative event, as a responsive interaction between social beings. The second category involves the fact that an apparently initial utterance is never actually the first utterance in any sense. In effect, every word or utterance looks back to the word or utterance it is answering, while simultaneously looking forward to the anticipated word or utterance it will partly determine in advance (this is the dialogic property of language attributed to workpractices. See below). The third category involves the social basis of meanings since Bakhtin viewed language and thought as intertwined. For Bakhtin, language cannot exist without thought, nor can thought exist without language, consequently both are social not individual. Refer to Dore (1995, 151-176) for a detailed explication of the social constitution of the individual. In applying Bakhtin's concepts to information systems in organisations, workpractices may be defined as texts which conform to Bakhtin's notion of the dialogic. The characteristic of workpractices as 'negotiated', proposed above, accords with Bakhtin's theories of text (Todorov 1984; see also the development of Bakhtin's work by Kristeva reviewed in Noth 1990, 321-324). This is demonstrated in the ways that workpractices are actively renegotiated by relevant social subjects, so that workpractices may exhibit more than one preferred realisation. However, the imposition of information systems into workpractices often acts to create an opposite tendency toward what Bakhtin refers to as the monological, or "the reduction of potentially multiple 'voices' (or characters) into a single authoritative voice ...[reducing the production of actualised meaning which] is sometimes inescapable." (Fowler 1987, 58-60), refer to Figure $1 \mathrm{~b}$.

Translinguistics is especially useful as a means for theorising how systems position users and others in organisations, and for providing a dynamic view of systems use. However, it does not provide methods for the analysis of actual work texts (for example transcripts) in specific situational and cultural contexts. Bakhtin was critical of the traditional linguistics of his day, developing substantial critiques of formalism and structuralism in linguistics. Specifically, he viewed traditional linguistic theories as monologic in that they attempting to account for discourse as if it consisted of single meanings. Therefore, translinguistics resists the kind of operationalisation necessary in a design discipline such as information systems. In order to study texts associated with workpractices, we need methods which can be applied to the task. A text-semiotic model of language called Systemic-functional linguistics (SFL) developed by Halliday (1985), and elaborated into the relatively new field of social semiotics (Kress 1985; Hodge and Kress 1988; Thibault 1991), is used to analyse transcripts associated with workpractices ${ }^{2}$. Theoretical affinities ${ }^{3}$ can be identified between Translinguistics and SFL which permit them to be used in conjunction with each other (see Table 1).

In addition, SFL genre theory developed by Martin (1992, 493-590), is used to analyse transcripts in order to derive the typical arrangement of stages in the enactment of a specific workpractice and its associated information system (the generic analysis and the genre digraph notation used here are provided in Clarke 1998). Genre analysis demonstrates that workpractices are negotiated. Related realisations of a workpractice are shown as alternative sequences in a genre digraph. When information systems are associated with workpractices, these technologies are also negotiated albeit from the point of view of the workpractice. From a social semiotic perspective, negotiating the typical arrangement of stages in a workpractice corresponds to an adoption of the dominant reading position of the system feature. The reading position is adopted by users who comply with the dominant discourses informing the workpractice, that is, the discourses which produce the 'coherence' of the workpractice. From this position, the system feature will appear to be the most obvious, natural, and uncontested negotiation of the workpractice. In adopting the dominant reading position, users comply with those discourses which produce centripetal forces tending to a monological, or integrationist instance of systems use. 
Current genre theory emphasises a synoptic view of genre, and as a consequence it is not well suited to explaining divergences from the typical arrangement of stages in workpractice genres. Translinguistics can be of use in theorising these atypical realisations of workpractice genres, as an adoption by users of a non-dominant, resisting subject position. At times users may: (i) re-negotiate one type of workpractice into a different form of workpractice, which still has the same overall purpose although realised by different means, or (ii) re-negotiate a workpractice into a completely different form. These new forms may not be organisationally sanctioned. As a consequence, resistant readings of a workpractice and its associated system features run the risk of failure in organisational contexts, in so far as the pragmatic goals of the workpractice may not be achieved. In some contexts, resistant readings may be viewed as an infringement of workplace regulations, best practice agreements or relevant acts of parliament. However, in some circumstances the adoption of a non-dominant (resisting) subject position may lead to a successful renegotiation of the workpractice. By adopting a non-dominant subject position, users mobilise discourses that produce centrifugal forces tending to a dialogic or separationist instance of systems use. Here, an associated information system may be used in an unorthodox way, or effectively bypassed using a manual work-around.

\section{EXEMPLIFICATION: INTEGRATION AND SEPARATION IN SYSTEMS USE}

In order to exemplify the theoretical approach to integration and separation in systems use described above, two examples are drawn from a longitudinal study of an information systems in its organisational context (see Clarke 1996, 1998). ALABS (Automated Library and Borrowing System) was a Transaction Processing System (TPS) developed by staff at the Microcomputer Laboratories (MCL), University of Wollongong, to implement the Loan and Return of a variety of items to its clients including software (on disks), manuals and hardware. It was a stand-alone system developed prior to wholesale networking of the MCL. Both examples consist of: (i) a description of the case using SFL genre theory and (ii) a reappraisal using translinguistics.

\section{Student Loans}

Many actual instances of texts associated with a specific kind of work are analysed in order to develop a workpractice genre. Each text is recorded, transcribed, and analysed for its constituent genre elements. The results of this analysis are sequences of genre elements, one sequence for each text. These sequences are merged together to form a digraph representation of the genre, where triangular symbols represent the start and end of the genre, labelled circles represent the constituent elements of the genre, and where arcs indicate one or more possible alternative sequences between elements of the genre. 
Table 1: Theoretical Affinities between relevant terms in Translinguistics and Systemic Functional Linguistics, presented across rows.

\begin{tabular}{|c|c|}
\hline Translinguistics & Systemic Functional Linguistics \\
\hline $\begin{array}{l}\text { social subjectivity } \\
\text { - emphasises the way in and by which the social } \\
\text { domain discursively constitutes subjects } \\
\text { subjects navigate a maze of organisational } \\
\text { discourses in workplaces }\end{array}$ & $\begin{array}{l}\text { social roles (tenor) } \\
\text { - theorised as a component of Register, tenor } \\
\text { involves established role relationships in texts }\end{array}$ \\
\hline $\begin{array}{l}\text { environment } \\
\text { - “...constitutes [a social subject's] situation in } \\
\text { its entirety..." (Roberts in Morris ed/ 1994, } \\
250 \text { ) in terms of purview and also those } \\
\text { elements which are provided by others }\end{array}$ & $\begin{array}{l}\text { context of culture (Malinowski 1923) } \\
\text { - theorised using the contextual strata of Genre } \\
\text { (Martin 1992, 493-588) } \\
\text { - can be glossed as societal and organisational } \\
\text { culture in the study of workpractices }\end{array}$ \\
\hline $\begin{array}{l}\text { purview } \\
\text { - "the limited extent of [a social subjects] ... } \\
\text { vision (literally and figuratively) as an } \\
\text { individual consciousness (q.v.), or as the } \\
\text { member of a social group" (Roberts in Morris } \\
\text { ed/ 1994, 250) }\end{array}$ & $\begin{array}{l}\text { context of situation (Malinowski 1923) } \\
\text { - theorised using the contextual strata of Register } \\
\text { (Martin 1992,493-588) } \\
\text { - viewed as "everything significant that was going } \\
\text { on concurrently with the speech activity." (Hasan } \\
\text { undated, 10) }\end{array}$ \\
\hline $\begin{array}{l}\text { genre } \\
\text { - } \quad \text { the particular way by which consciousness } \\
\text { models experience... broadly correspond[ing] } \\
\text { to... artistic genres (Roberts in Morris ed/ } \\
\text { 1994, 248) } \\
\text { a specific type of genre, the speech genre is } \\
\text { divided into primary speech genres (e.g. } \\
\text { ordering lunch), and secondary speech genres } \\
\text { (e.g. workpractice texts) }\end{array}$ & $\begin{array}{l}\text { genre } \\
\text { - using Martin's (1992) stratified model of SFL, } \\
\text { genre becomes its own contextual strata, see } \\
\text { context of culture } \\
\text { viewed as synoptic and dynamic, although all } \\
\text { methods emphasise the former, while some } \\
\text { research has raised doubts about the possibility of } \\
\text { the latter (see Hasan undated, 10) }\end{array}$ \\
\hline $\begin{array}{l}\text { utterance } \\
\text { - any stretch or unit of language as small as a } \\
\text { word or as large as a text } \\
\text { not a purely linguistic concept but an } \\
\text { encounter between a social subject's self } \\
\text { consciousness, mind, and the world with all its } \\
\text { socio-historical meaning (paraphrase of } \\
\text { Roberts in Morris ed/ 1994,251) }\end{array}$ & $\begin{array}{l}\text { text } \\
\text { the text is the unit associated with the discourse- } \\
\text { semantic strata in Martin's (1992) model: } \\
\text { supported below by two 'lower level' language } \\
\text { strata, and above by two 'higher level' contextual } \\
\text { strata (Register and Genre) } \\
\text { considered as both product (eg. transcript) and as } \\
\text { a (social) process }\end{array}$ \\
\hline $\begin{array}{l}\text { meaning } \\
\text { opposed to any fixed notion of meaning, } \\
\text { rejecting views of meaning as totally text- } \\
\text { bound, or views of meaning as the product of } \\
\text { exclusively extra-textual factors (paraphrase } \\
\text { of Roberts in Morris ed } / 1994,249 \text { ) }\end{array}$ & $\begin{array}{l}\text { meaning } \\
\text { - SFL conforms to a contextual theory of meaning, } \\
\text { that is, meaning is ultimately derivable from its } \\
\text { observed context (paraphrase of Nöth } 1990,100 \text { ) } \\
\text { meaning is not determined, rather it is construed } \\
\text { as social semiotic (see Kress } 1995 \text {; Halliday } \\
\text { 1978) }\end{array}$ \\
\hline
\end{tabular}


The Student Loan workpractice is represented by a genre digraph in Figure 3. The collected texts form service encounters between a student (a client) and a labstaff member (a responsible agent) who operated the ALABS system. The most frequently occurring sequence of elements are arranged along the horizontal line which joins the start and end symbols of the digraph. Generally students and/or labstaff would start the workpractice by exchanging salutations (represented by a phatic Greeting element) prior to establishing the required items (represented by the Service Request element). On occasion the phatic Greeting element is not realised in Student Loan texts, indicated by the curved arc in Figure 3, and both client and responsible agent move directly to resolving the SR element. At the Identification Sought element, students are required to provide their Student Identification (SID) card to the labstaff member for scanning into ALABS. Students must meet the following criteria in order for the workpractice to continue: (i) the student must be currently enrolled on ALABS; (ii) they must have a valid SID card; and (iii) they must not have any outstanding loans. Failure to meet any of these criteria will likely lead to the termination of the workpractice. The SID card is retained by the labstaff for the duration of the loan. Once the IS element has been completed, the requested items are provided to the student during the Materials Out element. A subsequence consisting of MO and SR may occur when the student requests additional items. MO is generally followed by the phatic 'leave taking' talk of the Finis element. Alternatively, the arc connecting MO to the end of digraph symbol, shows a less common path where $\mathrm{F}$ is not realised. In order to enrol students on ALABS, a distinct Regulations and Enrolment subsequence was inserted between IS and MO.

During interviews conducted with participants engaged in Student Loans, an incident was recounted in which a student who had lost their SID card, provided an expensive watch as collateral against the software they were borrowing. In this case the IS element was renegotiated into an element whose function more closely approximated the $\underline{V}$ alue of a retained Item. The participants conducted the loan manually created a negotiated separation. Between the workpractice and the system, shown by dashed lines in Figure 3 . The users jointly renegotiated one type of workpractice into a completely different form of workpractice, despite the fact that the new form was neither sanctioned within the organisation nor supported by ALABS. This atypical realisation of the Student Loan workpractice is not explainable within traditional SFL genre theory, which has no provision for a change in the function of a 'mandatory' genre element without a corresponding change in genre.

I regard the negotiated separation as an instance of a workpractice exhibiting dialogism. Systems features have a tendency to be monological, often designed with a particular set of sectional interests firmly in mind (of the designer) and often employing a managerial or analytical perspective. Most traditional design practices and methodologies lead to the production of systems that in use reduce the number of 'voices' in workplaces. Furthermore, those systems which have embedded security and identification features (IS) are often impossible for workers and clients to renegotiate and become 'inescapable' in Bakhtin's terms. Many transaction processing systems (TPS) in administrative contexts are so 'brittle' in use, that workers and clients may renegotiate them 'out of the picture' entirely. The system will be bypassed and a manual work-around thus realising a new form of workpractice.

\section{Tutor Loans and Returns}

Tutors were responsible for teaching classes in the computer laboratories during Supervised Laboratory Times. A responsible academic known to the Labstaff introduced new Tutors to the Microcomputer Laboratories. Once the tutors' details were entered into ALABS, a unique two-digit barcode was assigned to them in the Barcode Book that resided at the service desk. The two-digit barcode enabled the quick entry of the Tutor details during Tutor Loan and Return operations. Prior to the start of their class, a tutor would pick up two or more boxes of disks (10 disks per box) and a Class Loan Form. The disks had been sorted into boxes by the Labstaff prior to the start of the class. Because all the Supervised Laboratory Times were pre-booked, Labstaff would prepare boxes of the disks in advance of the arrival of the Tutor at the service desk. No transcripts are available for these workpractices, however, the staging of these service encounters has been reconstructed from interviews with participants who were involved with them. The genre digraphs for these service encounters are available in Clarke (1998), but are omitted here due to space restrictions. 
Figure 3: The Student Loan Genre represented using the digraph notation (after Clarke 1998). The typical staging of this workpractice is shown using solid lines. The dashed lines show an instance where IS is renegotiated into an entirely different element, the Value of a retained Item. This realisation of the Student Loan genre involves a negotiated separation between the system and the workpractice, which cannot be explained using SFL genre theory.

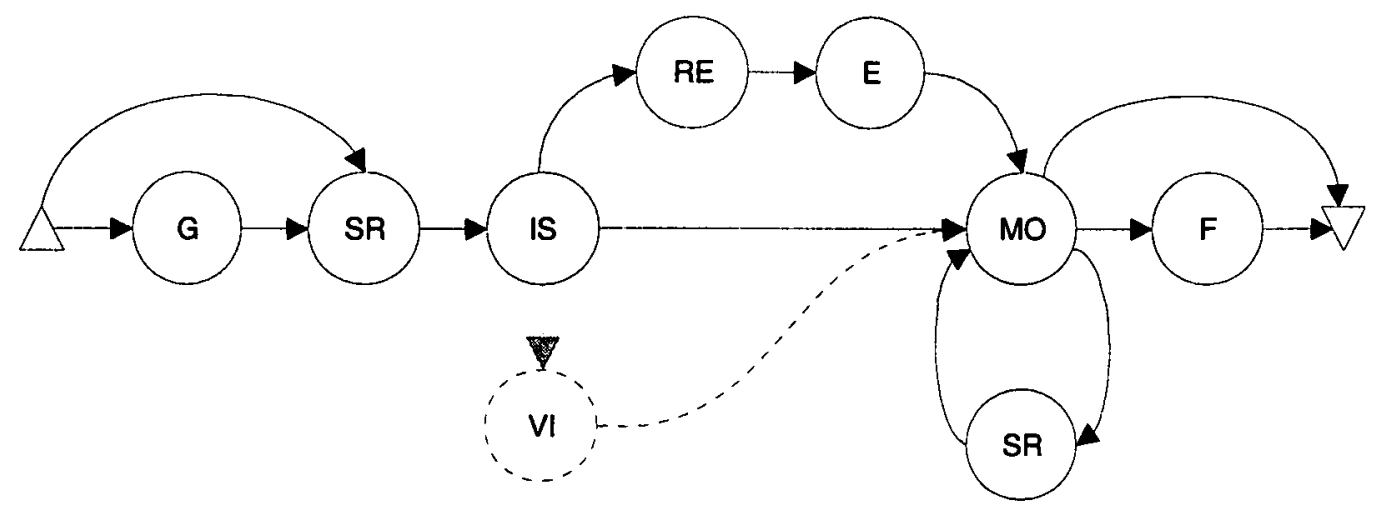

Tutor Loans and Returns were unique to ALABS. While all other users were only ever involved in a single location at any one time- the Service Desk, Tutors were required to function in two distinct locations: the Service Desk where the Tutor borrowed or returned software items, and the teaching laboratories where these items were used. Tutors involved in a Tutor Loan service encounter, received both the Class Sets of Disks and a so-called Class Loan Form. The Class Loan Form, a written text, acted as a shared material that bridged two locations. The Class Loan Form was the means by which Tutors acted as surrogate Labstaff members responsible for conducting manual Student Loans in teaching laboratories during Supervised

Laboratory Times. Once in a laboratory, the Tutor was required to record the student number and disks' details on the Class Loan Form, so that an audit trail could be maintained for the use of each disk. The recording of details on the Class Loan Form by Tutors and the distribution of disks to students during a Supervised Laboratory Time formed a service encounter, referred to as the Class Loan. At the end of a tutorial, the Tutor was required to collect all disks from students. Generally this involved 'ticking off' each returned disk on the Class Loan Form. This workpractice also constituted a service encounter, which is referred to as a Class Return. Upon completion of the Class Return, the Tutor returned the Class Sets of Disks and the completed Class Loan Form to the Labstaff member at the Service Desk. The resulting workpractice formed a service encounter called a Tutor Return. See Figure 3, which shows the configuration of these workpractices. 
Figure 3: Configuration of Tutor Loan (a) and Tutor Returns (b) Workpractices in ALABS as nested service encounters.

(a)

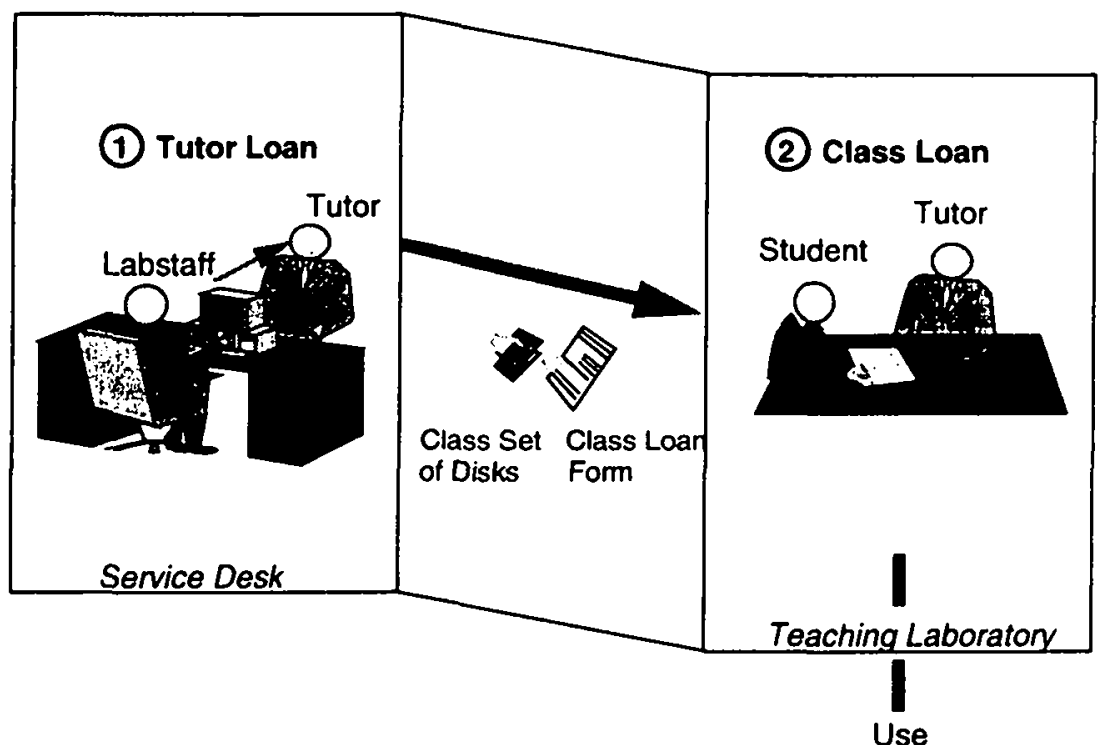

(b)

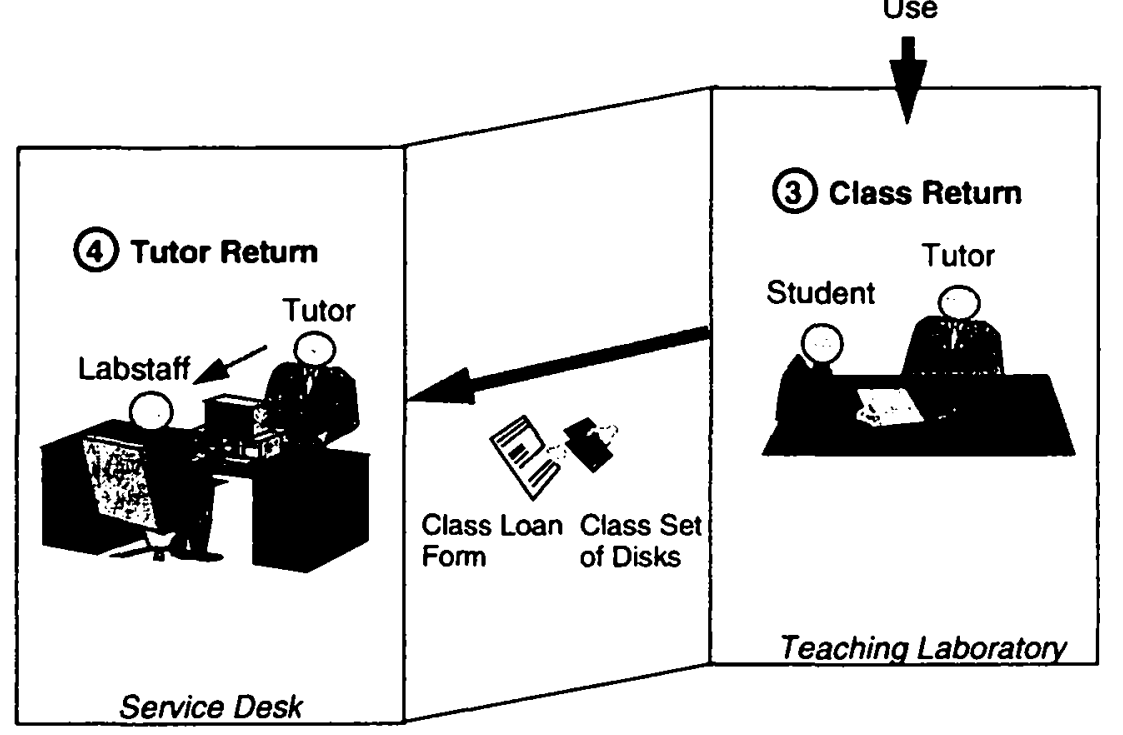

The success of a Tutor Return depends on the successful completion of the Class Return, Class Loan and Tutor Loan that preceded it. Tutors were dependent on the Labstaff to provide them with the correct type of disks, the correct number of disks and at the appropriate level of quality (zero defects or no faulty disks). If one or more of the disks in a Class Set provided during the Tutor Loan was faulty, then delays would occur in the Supervised Laboratory class while either (i) students moved to other machines or exchanged disks between themselves, or (ii) if the Tutor is forced to leave the class to replace faulty disks at the Service Desk. Situation (i) increases the likelihood of erroneous attribution of disks to students, while situation (ii) increases both the likelihood of erroneous attribution of disks, as well as the possibility of mislaying additional disks brought into the Laboratory by the Tutor after the Tutor Loan had taken place. The Labstaff members in situation (ii) required vigilance, so that these additional disks were also accounted for during the Tutor Return. Furthermore, if the Class Loan service encounter was not correctly completed either the (i) student numbers, (ii) disk numbers, (iii) or both, might not be correctly recorded on the Class Loan Form, and the effectiveness of the Class Return and Tutor Return would be compromised.

In effect, Tutor Loans, Class Loans, Class Returns, and Tutor Returns constitute what the author calls a nested service encounter. The concept of nested service encounters and the interdependencies between several service encounters and written texts have never been described in the SFL literature. Tutor Loan and Return features demonstrate the extension of the system into other locations through organising materials and discursively positioning users within the workplace. This case demonstrates an indirect integration where centripetal forces tend towards the monologic. Additional system features were dedicated to ensuring compliance from Tutors (for example, Overdue Loan Notices printed daily). Interestingly, according to a systems perspective only the Tutor 
Loan and Tutor Return operations would be considered part of ALABS. In effect, an automation boundary would be drawn separating the location of the Laboratory from the location of the Service Desk. The Class Loan Form would not be seen as a shared material but rather as data which was only visible at the start and conclusion of the Tutor Loan is started, and at the time the Tutor Return is concluded. In contrast, a systemic semiotic perspective does not recognise the existence of an automation boundary as inevitable or obvious. Rather it may be seen as a negotiable feature entirely dependent on the specific view of the relation between workpractices and IS, if at all.

\section{CONCLUSIONS}

In this paper, the author has attempted to re-theorise Integrationist and Separationist views of systems use by examining specific systems features notionally developed to support several workpractices. The dialectic between Integrationist and Separationist views presumed by Goldkuhl (1993), was seen to be a dichotomy. Derrida's reading tactics were applied to this dichotomy. The hinge term 'negotiation' was identified which could form a logical precondition for the dichotomy. Concepts from Bakhtin's social semiotics were used to theorise 'negotiation'. Integration in use was theorised as monologism, the tendency towards associated with centripetal forces, while separation in use was theorised as dialogism, the tendency associated with centrifugal forces. Despite providing a useful way of theorising a dialogical relationship for IS, Bakhtin's Translinguistic project purposefully resists efforts at operationalisation. Consequently, relevant concepts from Systemic Functional Linguistics- a semiotic model of language- were selected in order to be able to undertake applied studies in information system use. No simple mapping exists between concepts and units in Translinguistics and Systemic Functional Linguistics, however, theoretical affinities may be established. Two examples were used to test the veracity of these theoretical affinities.

Spoken and written language texts associated with actual workpractices and supported by system features of an information system (ALABS at the Microcomputer Laboratories), were collected and analysed using the Genre theory of Systemic Functional Linguistics, and reinterpreted using concepts from Translinguistics. The Student Loan example illustrates the active renegotiation by participants of what would otherwise be considered mandatory components of a workpractice. Augmented with a translinguistic account, the Student Loan is seen as an instance of a negotiated separation between a workpractice and its system feature, demonstrating centrifugal forces tending towards the dialogic. The Tutor Loan and Return example, comprising two service encounter genres supported by the system and two which are not. The Tutor Loan and Return demonstrates the extension of the system into other locations that the system cannot directly control. In a translinguistic account, such practices are made possible through the positioning of users within the workplace. This case demonstrates an indirect integration where centripetal forces tend towards the monologic. The concepts of negotiated separation and indirect integration, observed in these case studies have not previously been described in the Systems Design or Systems Use literatures.

\section{Notes}

1 Emerging applied semiotic fields, variously referred to as organisational semiotics (Stamper 1995), computer semiotics (Andersen 1992), semiotic engineering (de Souza 1993), computational semiotics (Vogel 1997) and semio-informatics (Clarke 1995), can be usefully classified according to their respective points of departure. Organisational semiotics and semio-informatics take the organisation as their point of departure while following a trajectory which leads to computer systems, information systems and technologies. However, computer semiotics, semiotic engineering and computational semiotics use computer systems, information systems and technologies as a point of departure while following a trajectory which leads to the organisation.

2 While the combination of Bakhtin's Translinguistics and Halliday's Systemic Functional Linguistics is usually considered as part of Social Semiotics (see Thibault 1991), the author uses the more specific term Systemic Semiotics, to characterise the theoretical approach adopted here.

3 The term 'affinity' is used to designate a theoretical connection between a concept from one body of theory to one or more concepts in the other body of theory, and is synonymous with the qualitative analysis term theoretical triangulation (Miles and Huberman 1988).

\section{Acknowledgments}

My thanks go to Efi Hatzimanolis of the Communications and Cultural Studies Program, Faculty of Arts, University of Wollongong, Australia for her detailed critical reading of this paper. This research was conducted 
under the auspices of the System in Context (SysCo) Research SIG of the Information Systems in Organisations (ISORG) Research Group, at the Department of Business Systems, University of Wollongong, Australia.

\section{REFERENCES}

Andersen, P. B. (1991) A Theory of Computer Semiotics: semiotic approaches to the construction and assessment of computer systems Cambridge Human Computer Interaction Series, UK: Cambridge University Press

Belsey, C. (1980) Critical Practice New Accents London: Methuen

Clarke, R. J. (1992) "Some Applications of Social Semiotics in Information Systems Discipline and Practice" in MacGregor, R.; Clarke, R. J.; Little, S.; Gould, T. and A. Ang eds/ (1992) Information Systems as Organisational Processes- ISOP'92: Proceedings of the Third Australian Conference on Information Systems Wollongong, NSW Australia, 67-79

Clarke, R. J. (1996) "The Persistence of Systems in Organisations: Genre Analysis of Systems Decommissioning" in Holmqvist, B.; Andersen, P. B.; Klein, H. and R. Posner eds/ (1996) Signs of Work: Semiosis and Information Processing in Organisations Berlin, New York: Walter de Gruyter, 59-106

Clarke, R. J. (1997a) "Organisational Semiosis: Rethinking Integrationist and Separation-ist Views of Information Systems" Abstract in Sankey, M. R.; Gimate-Welsh, A. and P. Pellegrino eds/ (1997) Semiotics Bridging Nature and Culture Vlth International Semiotics Congress, Guadalajara, Mexico, July 14-18 1997, International Association for Semiotic Studies- Association Internationale de Sémiotique (IASS-AIS) and Asociación Internacional de Estudios Semióticos, 102

Clarke, R. J. (1997b) "An Information System in its Organisational Context: A Systemic Semiotic Longitudinal Case Study" Unpublished $\mathrm{PhD}$ Dissertation

Crowley, T. (1989) "Bakhtin and the history of language" in Hirschkop, K. and D. Shepard eds/ (1989) Bakhtin and cultural theory Manchester and New York: Manchester University Press, 68-90

Derrida, J. (1988) Limited Inc Evanston, Il.: Northwestem University Press

de Souza, C. S. (1993) "The semiotic engineering of user interface languages" International Journal of ManMachine Studies 39, 753-773

Dore, J. (1995) "The Emengence of Language from Dialogue" in Mandelker, A. ed/ (1995) Bakhtin in Contexts: Across the Disciplines Evanston Press: Northwestern University Press, 151-176

Fowler, R. ed/ (1987) A Dictionary of Modern Critical Terms London and New York: Routledge

Goldkuhl, G (1993) "On the Relations between Information Systems and Organisational Activities: Integration and Separation As Thought Models" Research Report VITS June 1993 LiTH-IDA-R-93-18 Institutionen För Datavetenskap: Unversitetet och Tekniska Högskolan, Linköping, Sweden

Halliday, M. A. K. (1985) Spoken and Written Language Australia: Deakin University Press

Hasan, R. (undated) The Conception of Context in Text mimeo, 188pp.

Hirschkop, K. (1989) "Introduction: Bakhtin and cultural theory" in Hirschkop, K. and D. Shepard eds/ (1989) Bakhtin and cultural theory Manchester and New York: Manchester University Press, 1-38

Hodge, R. and G. Kress (1988) Social Semiotics "Chapter 2: The Founding Fathers Revisited" United Kingdom: Polity Press, pp. 13-36

Holquist, M. ed/ (1981) The Dialogic Imagination: Four Essays by M. M. Bakhtin Translated by Carl Emerson and Michael Holquist, University of Texas Press Slavic Series, No. 1, Austin: University of Texas Press

Kress, G. R. (1985) Linguistic Processes in Sociocultural Practice Australia: Deakin University Press

Malinowski, B. (1923) "The problem of meaning in primative languages" in Ogden, C. K. and I. A. Richards (1923) The Meaning of Meaning London: Kegan Paul, Trench Trubner

Mandelker, A. (1995) "Logosphere and Semiosphere: Bakhtin, Russian Organicism, and the Semiotics of Culture" in Mandelker, A. ed/ (1995) Bakhtin in Contexts: Across the Disciplines Evanston Press: Northwestern University Press, 177-190

Miles, M. B. and A. M. Huberman (1988) Qualitative Data Analysis: A Sourcebook of New Methods Newbury Park: Sage Publications

Roberts, G (1994) "A Glossary of Key Terms" in Morris, P. ed/ (1994) The Bakhtin Reader: Selected Writings of Bakhtin, Medvedev, Voloshinov London: Edward Arnold, 245-252

Norris, C. (1982) Deconstruction: Theory and Practice London and New York: Methuen

Nöth, W. (1990) Handbook of Semiotics Bloomington and Indianapolis: Indiana University Press

Pechey, G (1989) "On the borders of Bakhtin: dialogisation, decolonisation" in Hirschkop, K. and D. Shepard eds/ (1989) Bakhtin and cultural theory Manchester and New York: Manchester University Press, 39-67

Threadgold, T. (1986) "Introduction: Semiotics Ideology Language" in Threadgold, T.; Grosz, E. A.; Kress, G. and M. A. K. Halliday eds/ (1986) Semiotics Ideology Language Sydney Studies in Society and Culture No. 3, Sydney, Australia: The Sydney Association for Studies in Society and Culture, 15-60 
Thibault, P. J. (1991) Social Semiotics as Praxis: Text, Social Meaning Making, and Nabokov's Ada Theory and History of Literature, Volume 74 Minneapolis and Oxford: University of Minnesota Press

Todorov, T. (1984) Mikhail Bakhtin: The Dialogical Principle Translated by Wlad Godzich Theory and History of Literature, Volume 13 Minneapolis: University of Minnesota Press

Williams, R. (1988) Keywords: A vocabulary of culture and society London: Fontana Press 